\title{
TI GER-based measurement of nursing informatics competencies: The development and implementation of an online tool for self-assessment
}

\author{
Kathleen M. Hunter, Dee M. McGonigle, Toni L. Hebda \\ College of Nursing, Chamberlain College, USA \\ Correspondence: Toni L. Hebda. Address: 170 Skyline Drive Hickory, PA 15340, USA. Email: thebda@chamberlain.edu.
}

Received: December 2, 2012

DOI : $10.5430 /$ jnep.v3n12p70

Online Published: May 20, 2013

URL: http://dx.doi.org/10.5430/jnep.v3n12p70

\section{Abstract}

Background/Objective: The aim of this research was to develop a reliable, valid instrument for self-assessment of perceived nursing informatics (NI) competencies. This article describes the development and validity assessment of the instrument.

Informatics competencies are deemed a necessity in today's technologically-rich healthcare delivery system. Work to identify essential informatics skills commenced shortly after the introduction of information technology into healthcare. In subsequent years, professional organizations and individual experts have established NI competencies needed at various levels of nursing practice, from entry level through advanced practice. The Technology Informatics Guiding Educational Reform (TIGER) Initiative represents one such effort.

The TIGER Initiative emerged in 2006 as a grassroots effort dedicated to the preparation of a clinical workforce capable of using information technology and informatics to improve the delivery of healthcare. TIGER quickly organized into several different collaborative groups, including one that identified a set of recommended informatics competencies for nurses in 2009. The TIGER effort listed NI competencies in three areas: basic computer skills, information literacy, and clinical information management but did not operationalize these competencies into an instrument that could be used for assessment purposes.

Methods: Three rounds of reviews were conducted. In the first review, the researchers examined TIGER competencies, removing duplicative terms and combining items with similar content. The second and third rounds of reviews were each done by two separate sets of three experts in nursing informatics. During the second round, the list from round one was examined for items to retain or add. Resulting items were reworded to reflect measurable behaviors and then subjected to a third round of reviews to establish content validity, using the content validity index (CVI) methodology.

Results: CVIs demonstrated moderate validity for the instrument, and items not deemed relevant to the objective of the instrument were deleted, reducing the number of the items on the instrument. The instrument was piloted by posting the invitation on the online discussion forum of a nursing informatics organization. An additional invitation was extended to a group completing a weekend-long NI course. There were 184 respondents. Most respondents ranked themselves as expert on the majority of items, although a lesser degree of confidence was seen with items related to information literacy

Conclusions: TIGER competencies provided a useful foundation for the creation of a feasible online instrument for self-assessment of levels of competency. Fewer respondents identified themselves as expert in information literacy 
competencies. The instrument developed for this research project could be useful in planning educational opportunities in NI.

\section{Key words}

Nursing informatics, Competencies, Informatics competencies

\section{I ntroduction}

In this article, the researchers present their work on developing and testing an online instrument for self-assessment of perceived competencies in nursing informatics (NI). This instrument is derived from a set of NI competencies published by the Technology Informatics Guiding Educational Reform (TIGER) Initiative in $2009^{[1]}$. The TIGER Initiative emerged in 2006 as a grassroots effort dedicated to the preparation of a clinical workforce capable of using technology and informatics to improve the delivery of healthcare ${ }^{[2]}$.

The purpose of this research was to develop a reliable, valid instrument for self-assessment of perceived nursinginformatics competencies. Discussed in this paper are the research aim, or purpose, some definitions of the concept of competency, previous work on instruments to assess NI, the instrument-development process, assessment of validity, and some preliminary analysis of the results of a pilot test.

\subsection{Review of the literature}

Since the advent of computer systems in healthcare settings, nurses and nurse educators have been urged to acquire or teach competencies in using this technology. As the domain of nursing informatics emerged, experts asserted that nurses practicing in all domains and all settings need to be competent in selected aspects of nursing informatics. Staggers, Gassert, and Curran provide an excellent historical examination of experts' opinions on the need to ensure all nurses can effectively use information technologies in their practice ${ }^{[3]}$.

Private and public organizations also have advocated the development of informatics competencies, identifying nursinginformatics competencies through the collaborative work of experts. Organizations involved in identifying NI competencies include the American Nurses Association (ANA); the American Medical Informatics Association (AMIA); the Healthcare Information and Management Systems Society (HIMSS); the National League for Nursing (NLN); and the TIGER Initiative (now the TIGER Initiative Foundation).

To gain an understanding of competency, we first need to look at how competency might be defined. Interestingly, most research reports on nursing-informatics competencies do not define this concept. In 1989, Grobe presented a set of NI competencies developed by an international group of informatics nurses ${ }^{[4]}$. For this project, competency was seen as a sufficient amount of knowledge, judgment, skill, or strength. What these are sufficient for is not identified. Lucia and Lepsinger formulated a general definition of competency as knowledge-skill-attitude sets that correlate with performance on the job ${ }^{[5]}$. These are measurable against accepted standards and improvable by training or development. Specific competencies focused on knowledge-skill-attitude sets for managers. The Joint Commission views competency as skills, knowledge, and capability necessary for defined expectations; this definition is found in material on competency assessments in the 2005 handbook ${ }^{[6]}$.

Competency, then, is a concept applicable to multiple situations. At its most basic level, competency denotes having the knowledge, skills, and ability to perform or do a specific task, act, or job. Depending on the context, competency can refer to adequate or expert performance. For this research, competency was used to mean adequate knowledge, skills, and ability. Nursing-informatics competency was defined as adequate knowledge, skills, and ability to perform specific informatics tasks. 
Nurse researchers have been working to identify needed NI competencies for some time ${ }^{[3,7-9]}$; Staggers, Gassert, and Curran ${ }^{[3]}$ summarized the state of this research. A review of literature by Carter-Templeton, Patterson, and Russell on development or identification of NI competencies showed variation among the resulting sets of competencies ${ }^{[10]}$. These authors recommended establishment of a single, general list of competencies that can be utilized by nurses at all levels.

\subsection{Instruments to assess $\mathrm{NI}$ competencies}

The focus of the research discussed in this article is on measuring NI competencies. Unlike the identification of competencies, measurement is a less-developed area.

McNeil, et al. reported a study of nursing-informatics competencies using a researcher-developed survey instrument ${ }^{[9]}$. These researchers sought to examine how deans or directors of undergraduate and graduate nursing programs perceived the NI competencies and knowledge of their students, the extent to which their faculty were prepared to teach NI, and the NI competencies needed by practicing nurses. This research used an instrument titled Information Technology Education in Nursing Curricula Survey (ITENCS), which was developed from a review of NI literature and reported that content validity was achieved by expert review. Content-validity methodology and data were not provided. The online version of the ITENCS was comprised of 37 items, addressing 7 core content domains and 25 specific content categories. Survey questions collected both qualitative and quantitative data. In the published report, neither the complete instrument nor examples of questions were provided. Reliability data was absent.

Ornes and Gassert ${ }^{[11]}$ described the results of a nursing school's evaluation of informatics content in its baccalaureatedegree program. To examine the syllabi for each course in the curriculum, a new instrument was developed. The nursinginformatics-competency categories identified by Staggers et al. were used to create a matrix, with the competency categories forming the left-hand column, and identifying information for each course in a semester listed in rows across the top. Four matrices - one for each semester - were created. As each syllabus was reviewed, the cells were marked by one investigator, noting the presence or absence of content related to the elements of a competency category. Information on instrument testing for reliability, validity, and other characteristics was not included in the article.

Providing continuing education via the Internet is believed to make such education more readily available to registered nurses, who work varying hours and have difficulty attending classes offered at fixed times and places. Lin, Lin, Jiang, and Lee ${ }^{[12]}$ explored the relationship between competency in nursing informatics and nurses' satisfaction with continuing education provided over a network. These researchers developed a study-specific questionnaire with items on networkeducation satisfaction drawn from the literature, experts' opinions, nursing experiences of the researchers, and nursinginformatics competencies identified by Jiang et al. ${ }^{[8]}$ Lin and colleagues reported that instrument validity was assessed through testing of a content validity index (CVI) via an expert panel ${ }^{[12]}$. Following revision of the questionnaire, based on the CVI results, another panel of experts reviewed the instrument for understandability. No further revisions were done. The authors also described reliability testing through a pilot test, with Cronbach's alpha of .90 calculated for the competency portion of the questionnaire and the network-education component yielding a Cronbach's alpha of 0.92.

Seeking to identify a best way to determine NI competencies, Elder and Koehn ${ }^{[13]}$ compared how pre-licensure nursing students assessed their competencies with computers to a computer-based assessment of those same students. The survey questionnaire for this study was developed by the researchers and focused on topics related to using office-suite software, operating a computer, and conducting literature searches. The computer-based assessment, also developed by the researchers, addressed the same themes. Missing from this report was information on competency definitions, sources for the instrument content, and reliability and validity estimates.

Fetter ${ }^{[14]}$ studied information-technology (IT) competencies of pre-licensure nursing students at the end of their academic program. These graduating seniors completed a questionnaire developed earlier by the researcher, which asked the respondents to self-identify their skills with IT. The instrument was based on novice-level informatics competencies 
identified by Staggers et al. Competency was not defined, and data on instrument performance was not included in the published article.

Yoon, Yen, and Bakken reported an examination of psychometric properties of the Self-Assessment of Nursing Informatics Competencies Scale (SANICS) ${ }^{[15]}$. SANICS is a 93-item rating scale developed from two sources. One source was selected items from the competencies developed by Staggers et al. Additional items were developed by the researchers. A competency definition was missing.

\subsection{TIGER initiative competencies}

The set of nursing informatics competencies published by the TIGER Initiative contains three categories of competencies: basic computer skills, information literacy, and clinical information management. The basic-computer-skills category was drawn from the European Computer Driver License (ECDL) and includes 108 non-duplicated items. Information literacy is addressed by 47 items adapted from the American Library Association's information-literacy standards ${ }^{[16]}$. The Health Level Seven electronic health-record-system functional model's direct-care components were adapted to form 76 items for the clinical information management category ${ }^{[17]}$.

This research project focused on developing a self-assessment of NI competencies, based on the TIGER competencies. The project we describe came about because faculty at Chamberlain could not find a research-based instrument for selfassessment of NI competencies. We chose to use the TIGER competencies because we support the work of this group. Originally, the NI faculty was looking for an instrument to use in the NI specialization track. After discussions with other faculty, the focus changed to an instrument to be used throughout our student populations and for faculty in all programs.

\section{Methods}

The specific aim of this research was to develop a reliable and valid online instrument for self-assessment of perceived competencies in selected nursing-informatics activities. This article presents the work on development of the instrument and initial validity assessment. We are planning a future publication that will focus on the quantitative analysis of data from the pilot study, including reliability estimates.

In this section, instrument development and assessment of the content validity index are related.

\subsection{I nstrument development}

Step 1: Each researcher independently reviewed one of the 3 subsets of competencies. The review focused on determining how many items were conceptually duplicated within a subset. If conceptual duplicates were found, the researcher rewrote an item to ensure all content in the conceptual duplicates was addressed and deleted the now-extraneous items. The clinical-information-management subset of NI competencies had the greatest number of conceptual duplicates, resulting in a reduction of items from 76 to 12 . The subset of competencies for basic computer skills was reduced from 108 to 99 items, and the subset for information literacy shrank from 47 to 42 items.

Step 2: Using the published literature and collegial connections, three NI experts were identified and asked to review the three subsets. These experts were asked to examine each subset separately. Their focus was on identifying items to be retained, items to be removed, and items to be added. Interestingly, none of the independent reviews resulted in any changes to the subsets of NI competencies derived from the first step.

Step 3: The researchers now examined the wording of the competencies in each subset, dividing this effort among the team by each researcher taking one subset. The wording of the item was assessed for its fit with a behavioral focus. If necessary, being careful to retain the original concept of each item, the item was reworded to include one behavioral verb. 
Step 4: A fourth round of reviews, by an additional three nursing informatics experts, was conducted to assess content validity. In this round, three experts independently evaluated the extent to which each item in each subset was relevant to the instrument's purpose. A different form was provided for each subset. On each subset's form, the instrument's purpose was established as "Determine self-perceived level of competency with [name of subset] tasks". The expert reviewers noted the relevancy of each subset item on a scale of highly relevant, quite relevant, somewhat relevant, and not relevant.

Step 5: Using the experts' assessment of item relevancies and the method described by Waltz, Strickland, and Lenz ${ }^{[18]}$, a content validity index (CVI) was calculated for each subset of NI competencies. Then, we removed all items classified as 'not relevant' to the objective of the instrument. This enabled us to reduce the number of items in each subset. The information literacy subset went from 42 items to 25; the clinical information management subset's 12 items were reduced to 9 items; the subset of items on basic computer skills was shortened from 99 to 51 . No further changes were made to the items. Table 1 presents the calculated CVI for the original subsets of NI competencies and the revised subsets.

Table 1. Content Validity Index (CVI) for Each NI-Competency Subset before and after Not Relevant Items Removed.

\begin{tabular}{lll}
\hline Competency Set & CVI on Original Subset & CVI on Revised Subset \\
\hline Information Literacy & .75 & 1.0 \\
Clinical Information Management & .64 & 1.0 \\
Basic Computer Skills & .52 & 1.0 \\
\hline
\end{tabular}

Step 6: For each subset of NI competencies, the items were listed vertically. Four categories of perceived competency were offered as choices for each item. The category names were taken from the seminal work of Staggers et al: beginner, comfortable, proficient, and expert. Definitions for these self-perceived competency categories were not provided on the instrument. Respondents would self-determine the meaning of each competency. Table 2 displays the pilot-test version of the items for each subset.

\subsection{Scoring}

To collect quantitative data, each category was assigned a numerical value from 1 to 4: beginner (1), comfortable (2), proficient (3), and expert (4).

\subsection{Pilot test}

The pilot test of this instrument was conducted with the cooperation of an online discussion forum focused on nursing informatics. The participants in this forum were our research population. We obtained approval from Chamberlain's IRB. The content of the instrument was converted to the format of a Qualtrics ${ }^{\mathrm{TM}}$ online survey. Within the survey, each subset was presented in sequence, beginning with basic computer skills, followed by information literacy, and ending with clinical information management. Response choices were listed in the following sequence: expert, proficient, comfortable, and beginner/NA. NA was added to accommodate respondents who wanted to respond as 'not applicable'.

We posted an invitation to participate in the research on the online forum and included the URL of the survey's location. The duration of the survey was set at 14 days. We posted a reminder on the forum near the end of the time and closed the survey on the posted date. Additional respondents came from a group of individuals participating in a weekend-intensive nursing informatics workshop. These participants were provided with information about the survey and the URL. The resulting sample would be classified as purposive and non-random.

\subsection{Sample}

We had 184 participants, whose age ranged from 26 - 70, with a mean of 48-50 years. Not surprisingly, the majority were female. Of these respondents, 161 respondents were registered nurses (RNs). We did not ask for information on the professional status of those who were not registered nurses. Table 3 shows the breakdown of respondents by age, sex, registered nurses as opposed to other listserv participants, highest level of education achieved at the time of the study, 
years in nursing informatics, and certification status. Note that the number of responses in each category may not sum to 184, due to missing data.

Table 2. Pilot-test version of the items for each subset

\begin{tabular}{|c|c|c|}
\hline Subset & \multicolumn{2}{|c|}{ Items } \\
\hline \multirow{45}{*}{ Basic Computer Skills } & (1) & Describe the concepts of uploading and downloading \\
\hline & (2) & Activate a hyperlink \\
\hline & (3) & Define the term e-learning \\
\hline & (5) & Name ways to protect my computer and information \\
\hline & (6) & Start the computer and log on securely using a user name and password \\
\hline & (7) & Restart the computer using an appropriate routine \\
\hline & (9) & Shut down the computer using an appropriate routine \\
\hline & $(10)$ & Use available Help functions \\
\hline & $(11)$ & View the computer's basic system information \\
\hline & $(12)$ & Create a desktop icon \\
\hline & $(13)$ & Collapse, expand, restore, re-size, move, close a window \\
\hline & (14) & Create a folder and sub-folder \\
\hline & $(15)$ & Identify common file types \\
\hline & $(18)$ & Rename files, folders \\
\hline & $(19)$ & Move files, folders between folders and between drives \\
\hline & $(20)$ & Restore files, folders from the recycle bin/wastebasket/trash \\
\hline & $(21)$ & Use anti-virus software to scan specific drives, folders, files \\
\hline & $(22)$ & Change the default printer from an installed-printer list \\
\hline & $(23)$ & Open an application \\
\hline & $(24)$ & Create a new file \\
\hline & $(25)$ & Save a file to a location on a drive \\
\hline & $(26)$ & Close an application \\
\hline & $(27)$ & Open a file \\
\hline & $(28)$ & Close a file \\
\hline & (29) & Switch between open files \\
\hline & $(30)$ & Copy and paste content between files \\
\hline & $(31)$ & Display/ hide built-in toolbars \\
\hline & $(32)$ & Identify risks associated with on-line \\
\hline & $(35)$ & Recognize examples of social networking websites, Internet forums, chat rooms, on-line computer games \\
\hline & (36) & Recognize attempted phishing \\
\hline & (37) & Explain the importance of network etiquette (netiquette) \\
\hline & (38) & Identify possible problems when sending file attachments \\
\hline & (39) & Complete the To, Copy (Cc), Blind copy (Bcc), and subject fields in email \\
\hline & $(40)$ & Insert, remove a file attachment \\
\hline & $(41)$ & Save a draft of an e-mail \\
\hline & $(42)$ & Use a spell-checking tool and correct spelling errors \\
\hline & $(43)$ & Send an e-mail; send an e-mail with a low, high priority. \\
\hline & $(44)$ & Use the reply, reply to all function \\
\hline & $(45)$ & Forward an e-mail \\
\hline & $(46)$ & Add, remove message inbox headings like: sender, subject, date received \\
\hline & $(47)$ & Apply a setting to reply with, without original message insertion \\
\hline & $(48)$ & Flag an e-mail. Remove a flag mark from an e-mail \\
\hline & (49) & Identify an e-mail as read, unread. Mark an e-mail as unread, read \\
\hline & $(50)$ & Search for an e-mail by sender, subject, e-mail content \\
\hline & $(51)$ & Add contact details to an address book. Delete contact details from an address book \\
\hline & $(1)$ & Capture data and information related to clinical care \\
\hline & $(2)$ & Update data and information \\
\hline & (3) & Display on a screen \\
\hline & (4) & Print standardized (pre-formatted) reports \\
\hline Clinical Information Management & (5) & Demonstrate procedures that assure confidentiality of protected patient health information (PHI) \\
\hline & $(6)$ & Demonstrate procedures for maintaining security of PHI \\
\hline & (7) & Demonstrate procedures to maintain security of organizational information \\
\hline & (8) & Find information stored in the HIS to guide patient care (guidelines, standardized plans of care, protocols, etc.) \\
\hline & (9) & Communicate electronically with others such as colleagues, patients, other departments, and organizational units \\
\hline
\end{tabular}

(Table 2 continued on page 76) 
Table 2. (continued)

\begin{tabular}{|c|c|c|}
\hline \multirow[t]{2}{*}{ Subset } & \multicolumn{2}{|c|}{ Items } \\
\hline & (1) & Determine the nature and extent of the information needed \\
\hline & (2) & Describe information needed through key concepts and terms \\
\hline & (3) & Identify keywords, synonyms, and related terms for the information needed \\
\hline & (4) & Describe the available proprietary information systems (CINAHL, EBSCO, etc.) \\
\hline & (5) & $\begin{array}{l}\text { Determine the most appropriate methods for accessing information electronically : search engines, interfaces (the database } \\
\text { screens), and content available through a given system }\end{array}$ \\
\hline & (6) & State the risks and constraints of searching the Internet for needed evidence-based information \\
\hline & (7) & Use appropriate search language and parameters for selected system \\
\hline & (8) & $\begin{array}{l}\text { Assess the quantity, quality, and relevance of the search results to determine whether alternative information retrieval } \\
\text { systems or investigative methods should be utilized }\end{array}$ \\
\hline & (9) & $\begin{array}{l}\text { Evaluate information and its sources critically and incorporates selected information into his or her knowledge base and value } \\
\text { system }\end{array}$ \\
\hline & $(10)$ & Identify verbatim material that can be appropriately quoted \\
\hline & $(11)$ & Restate in your own words main concepts from a source \\
\hline \multirow[t]{14}{*}{ Information Literacy } & $(12)$ & $\begin{array}{l}\text { Compare information from various sources to evaluate reliability, validity, accuracy, authority, timeliness, and point of view } \\
\text { or bias }\end{array}$ \\
\hline & $(13)$ & Judge the scholarly nature of a source such as: physical appearance, advertising, peer review, references, footnotes) \\
\hline & $(14)$ & Analyze the structure and logic of supporting arguments or methods \\
\hline & $(15)$ & Determine the value added by the new information \\
\hline & $(16)$ & Synthesize conclusions based upon information gathered \\
\hline & $(17)$ & Use information effectively to accomplish a specific purpose individually or as a member of a group \\
\hline & $(18)$ & Articulate knowledge and skills transferred from prior experiences to meet information-need purpose \\
\hline & (19) & Manipulate digital text, images, and data to transfer from original source into new context \\
\hline & $(20)$ & Evaluate outcomes of the use of information \\
\hline & $(21)$ & Describe privacy and security of information \\
\hline & $(22)$ & Explain free versus fee-based access to information \\
\hline & $(23)$ & Use approved passwords and other forms of ID for access to information resources \\
\hline & $(24)$ & Describe how to preserve the integrity of information resources, equipment, systems and facilities \\
\hline & $(25)$ & Obtain, store, and disseminate text, data, images, or sounds legally \\
\hline
\end{tabular}

Certification in nursing informatics is hard to track. The data in Table 2 gives us some idea of where the specialty stands most are not certified in nursing informatics or in some other informatics certification. Further exploration of this issue would be interesting.

Just over one-half of the respondents had 2-5 years of experience in the field $(n=51)$. The next largest group had 6 - 10 years $(n=40)$. These numbers might reflect the growing demand for NI practitioners, coupled with an increase in NI graduate programs.

\section{Results and discussion}

This research was conducted to develop a reliable, valid instrument for self-assessment of perceived nursing informatics competencies since these competencies are deemed a necessity to be able to work in this technology and knowledge era. This article reports on the development and validity assessment of the instrument. Professional organizations and individual experts have established competencies needed at various levels of nursing practice from entry level through advanced practice. The TIGER initiative represents one such effort for informatics competencies.

We are just beginning to analyze the data related to the individual survey items. In the next table, we share some interesting results we do have. Not surprisingly, for each competency in each subset, the majority of the respondents classified themselves as experts. Interesting to us are the items where the majority did not classify themselves as experts. In Table 4, we have listed the specific items from each competency subset where the majority of respondents did not list themselves as expert (they chose proficient, comfortable, or beginner). The sub-category of information literacy had the most items where the majority of respondents did not classify themselves as expert. These information-literacy items tap the concepts of using bibliographic information systems, analyzing information search results, and evaluating information sources. Additional information-literacy items in this non-expert grouping were: comparing information sources, logical and structural analysis of information, determining added value of new information, and synthesizing conclusions. 
Table 3. Breakdown by Survey Respondents by Age, Sex, Professional Background, Highest Level of Education, Years in Nursing Informatics, and Certification Status

\begin{tabular}{|c|c|c|}
\hline Item & $\begin{array}{l}\text { Number of Respondents in } \\
\text { each subgroup }\end{array}$ & $\begin{array}{l}\text { Percentage of respondents per total } \\
\text { respondents (n) in each group }\end{array}$ \\
\hline \multicolumn{3}{|l|}{ Age $(n=163)$} \\
\hline $20-25$ & 0 & 0 \\
\hline $26-30$ & 4 & 2 \\
\hline $31-35$ & 6 & 4 \\
\hline $36-40$ & 13 & 8 \\
\hline $41-45$ & 14 & 9 \\
\hline $46-50$ & 23 & 14 \\
\hline $51-55$ & 45 & 28 \\
\hline $56-60$ & 40 & 25 \\
\hline $61-65$ & 15 & 9 \\
\hline $66-70$ & 1 & 1 \\
\hline $70+$ & 2 & 1 \\
\hline \multicolumn{3}{|l|}{ Sex $(n=164)$} \\
\hline M & 17 & 10 \\
\hline $\mathrm{F}$ & 147 & 90 \\
\hline \multicolumn{3}{|l|}{ Background/Profession $(n=164)$} \\
\hline Registered Nurse & 161 & 98 \\
\hline Other - not specified? & 3 & 2 \\
\hline \multicolumn{3}{|l|}{ Educational level $(n=164)$} \\
\hline Diploma & 3 & 2 \\
\hline Associate & 5 & 3 \\
\hline Bachelor of Science in Nursing & 30 & 18 \\
\hline Other Baccalaureate & 12 & 7 \\
\hline Master of Science/Master of Science in Nursing & 85 & 52 \\
\hline Other Master’s & 23 & 14 \\
\hline Doctor of Philosophy & 5 & 3 \\
\hline Other Doctorate & 1 & 1 \\
\hline \multicolumn{3}{|l|}{ Years of Experience in Nursing Informatics $(n=157)$} \\
\hline $2-5$ & 51 & 32 \\
\hline $6-10$ & 40 & 25 \\
\hline $11-15$ & 29 & 18 \\
\hline $16-20$ & 14 & 9 \\
\hline $21-25$ & 4 & 3 \\
\hline $26-30$ & 8 & 5 \\
\hline $31-35$ & 4 & 3 \\
\hline $36-40$ & 7 & 7 \\
\hline \multicolumn{3}{|l|}{ Certification in Informatics } \\
\hline \multicolumn{3}{|l|}{ Board Certification in NI ( $\mathrm{n}=161)$} \\
\hline Yes & 45 & 28 \\
\hline No & 116 & 72 \\
\hline \multicolumn{3}{|l|}{ Other Informatics Certification ( $\mathrm{n}=157)$} \\
\hline Yes & 18 & 11 \\
\hline No & 139 & 89 \\
\hline
\end{tabular}


Table 4. Items from Each NI Competency Set Where the Majority of Respondents did not Self-Identify as Expert

\begin{tabular}{ll}
\hline NI Competency Set & Items Where No Respondents Self-Identified as Expert \\
\hline \multirow{2}{*}{ Clinical Information Management } & Define e-learning \\
& Recognize examples of social networking websites, Internet forums, chat rooms, on-line \\
& Name options for recycling computer components, printer cartridges, and paper \\
& Recognize attempted phishing \\
& Describe the available proprietary information systems \\
& (CINAHL, EBSCO, etc.) \\
& Assess the quantity, quality, and relevance of the search results to determine whether \\
& alternative information retrieval systems or investigative methods should be utilized \\
& Evaluate information and its sources critically and incorporates selected information into \\
& his or her knowledge base and value system \\
& Compare information from various sources to evaluate reliability, validity, accuracy, \\
& authority, timeliness, and point of view or bias \\
Information Literacy & Analyze the structure and logic of supporting arguments or methods \\
& Determine the value added by the new information \\
& Synthesize conclusions based upon information gathered \\
\hline
\end{tabular}

The items where most of the respondents were not self-rated as experts reflected the cognitive domain in each of subsets, with $17 \%$ of the information-literacy items, $22 \%$ of the clinical-information-management items, and $4 \%$ of the basic computer skills items. These percentages were calculated from a simple hand count of the noted items, which was then compared against the total number of items in each group. A percentage was then computed from the resulting ratio. This result could be a function of learning on the job and not having formal education in NI. It could be that the participants are doing different tasks and do not feel proficient in tasks that they do not normally complete.

The following three items from the information-literacy subset are related to the same aspect - evaluating the value of information. A perceived absence of expertise in this area points to a need for more informatics education that can facilitate nurses' ability to move through the data-information-knowledge-wisdom (DIKW) pathway. Evaluating information value also is needed for effective evidence-based practice (EBP).

- Assess the quantity, quality, and relevance of the search results to determine whether alternative information retrieval systems or investigative methods should be utilized

- Evaluate information and its sources critically and incorporates selected information into his or her knowledge base and value system

- Compare information from various sources to evaluate reliability, validity, accuracy, authority, timeliness, and point of view or bias

There were two items in the clinical-information-management subset (see Table 4) where the majority of respondents did not claim expertise. These two items are related to use of social media. Based on their age and work setting, the majority might not be regular users of social networking or chats. Depending on their educational preparation, they might not have experienced or be familiar with e-learning.

The two items related to basic computer skills address recycling of printer waste and the concept of phishing (Table 4). Not seeing oneself as an expert in these areas could, again, be a function of informal training and lack of experience.

\section{Recommendations}

This article focused on instrument development. Extensive analysis of each item as well as quantitative and qualitative aggregate results will be reported in a future article. A primary recommendation from this work to date is to continue using 
the instrument with diverse groups, such as students in undergraduate and graduate programs, nurses in healthcare settings, and faculty. A secondary recommendation is to assess more closely, in future instrument use, how well the results can be used to guide independent and formal education in nursing informatics to enhance NI competencies.

\section{Conclusion}

The TIGER competency sets required some revision to incorporate measurable behaviors. The TIGER competencies are useful as a foundation for creating measurable competency sets. Content validity was estimated for the original set of items and used to revise the instrument. This online instrument is feasible and discriminates among levels of competency. Results from using this instrument could be useful in planning NI education opportunities.

\section{Authors' contributions}

The authors declare that this research and resulting article represent collaborative efforts from inception through the development and analysis of the self-assessment instrument and this report.

\section{Acknowledgements and funding}

The researchers would like to acknowledge Jennifer Alestock who was instrumental in the development of the instrument using Qualtrics online survey software and Chamberlain College of Nursing for their ongoing support of our research and scholarship.

\section{References}

[1] Technology Informatics Guiding Education Reform. Informatics competencies for every registered nurse: recommendations from the TIGER collaborative. Available from: http://www.tigersummit.com/uploads/3.Tiger.Report_Competencies_final.pdf.

Accessed November 29, 2012.

[2] The T.I.G.E.R. Initiative Foundation. (July 1, 2011) Improving informatics skills for clinicians, new foundation incorporates. Available from: http://www.thetigerinitiative.org/default.aspx. Accessed November 29, 2012.

[3] Staggers N, Gassert C, Curran C. Informatics competencies for nurses at four levels of practice. Journal of Nursing Education. 2001; 40: 303-317. PMid:11596683

[4] Grobe S. Nursing informatics competencies. Meth Inform Med. 1989; 28: 267-269. PMid:2622377

[5] Lucia AD, Lepsinger R. The art and science of competency models: pinpointing critical success factors in organizations. New York: Pfeiffer, 1999.

[6] Joint Commission Resources. Assessing hospital staff competence. Oakbrook Terrace, IL: Author, 2002.

[7] Desjardins KS, Cook SS, Jenkins M, Bakken S. Effect of an informatics for evidence-based practice curriculum on nursing informatics competencies. Int J Med Inform. 2004; 74:1012-20. PMid:16125454 http://dx.doi.org/10.1016/j.ijmedinf.2005.07.001

[8] Jiang WW, Chen, W, Chen YC. Important computer competencies for the nursing profession. J Nurs Res. 2004: 12: $213-226$. PMid:15362013 http://dx.doi.org/10.1097/01.JNR.0000387505.98877.6d

[9] McNeil B, Elfrink V, Pierce S, Beyead S, Bickford C, Averill C. Nursing informatics knowledge and competencies: a national survey of nursing education programs in the United States. Int J Med Inform. 2005; 74: 1021-1030. PMid:16046276 http://dx.doi.org/10.1016/j.ijmedinf.2005.05.010

[10] Carter-Templeton H, Patterson R, Russell C. An analysis of published nursing informatics competencies. Stud Health Technol Inform. 2009; 146: 540-545. PMid:19592901

[11] Ornes LL, Gassert C. Computer competencies in a BSN program. Journal of Nursing Education. 2007; 46: 75-78. PMid:17315566

[12] Lin J, Lin K, Jiang W, Lee T. An exploration of nursing informatics competency and satisfaction related to network education. J Nurs Res. 2007; 15: 54-65. PMid:17370233 http://dx.doi.org/10.1097/01.JNR.0000387599.17285.76

[13] Elder B, Koehn M. Assessment tool for nursing student computer competencies. Nurs Educ Perspect. 2009; 30(3); $148-152$. PMid:19606656

[14] Fetter M. Graduating nurses' self-evaluation of information technology competencies. Journal of Nursing Education. 2009; 48(2): 86-90. PMid:19260400 http://dx.doi.org/10.3928/01484834-20090201-05 
[15] Yoon S, Yen P, and Bakken S. Psychometric properties of the self-assessment of nursing informatics competencies scale. In Proceedings of NI 2009; 2009. Edited by Saranto K, Brennan P, Park H, Tallberg M. Ensio S. Amsterdam, Netherlands: IOS Press. 2009: 546-550. PMid:19592902

[16] American Library Association. Information literacy competency standards for higher education. 2000. Available from: http://www.ala.org/acrl/standards/informationliteracycompetency. Accessed December 1, 2012.

[17] Health Level Seven. HL7 EHR system functional model: a major development towards consensus on electronic health record system functionality. A white paper 2004. Available from:

http://www.hl7.org/documentcenter/public_temp_70FE670A-1C23-BA17-0C4FDCE8978D5AB0/wg/ehr/EHR-SWhitePaper.pd f. Accessed December 1, 2012.

[18] Watz, C, Strickland, O, Lenz, E. Measurement in nursing and health research, 4th edition. New York: Springer Publishing, 2010. 